\title{
Rationally Designed Self-Immolative Rotaxane Sensor Based on Pillar[5]arene for Fluoride Sensing
}

\author{
Qi Li, ${ }^{\dagger, a}$ Yitao Wu, ${ }^{\dagger, a}$ Yuezhou Liu, ${ }^{\text {a }}$ Liqing Shangguan, ${ }^{\text {a }}$ Bingbing Shi, ${ }^{*, b}$ Huangtianzhi Zhu ${ }^{*}$, \\ ${ }^{\dagger}$ Q.L. and Y.W. contributed equally to this work \\ a Department of Chemistry, Zhejiang University, Hangzhou 310027, P. R. China. \\ ${ }^{b}$ Key Laboratory of Eco-Functional Polymer Materials of the Ministry of Education, College of \\ Chemistry and Chemical Engineering, Northwest Normal University, Lanzhou 730070, P. R.
}

China.

\section{Supporting Information}

1. Materials and methods $\quad$ S2

2. Synthetic procedures of P5-R S3

3. NOESY spectrum of P5-R S8

4. UV-vis spectrua of P5-R before and after adding fluoride anion S9

5. ${ }^{1}$ H NMR spectrum of $\mathbf{P 5 - R}$ in presence of fluoride anion $\quad \mathrm{S} 10$

6. MALDI-TOF spectrum of P5-R in presence of fluoride anion S11

7. Time-dependent fluorescence spectra. $\quad \mathrm{S} 12$

8. The fluorescence spectra of P5-R in prescence of different anions. S13

9. Fluorescence titration for detection limitation $\quad \mathrm{S} 14$

10. X-ray crystal data for P5-R $\quad$ S15

11. The association constant between 1 and $2 \quad \mathrm{~S} 16$

12. References $\quad$ S16 


\section{Materials and methods}

All reagents are commercially available and used directly. A Bruker Avance DMX 500 spectrophotometer or a Bruker Avance DMX 400 spectrophotometer was used to record ${ }^{1} \mathrm{H}$ or ${ }^{13} \mathrm{C}$ NMR spectra with deuterated solvent as the lock; the internal reference was TMS or residual solvent. UV-vis spectroscopy was performed on a Shimadzu UV-2550 instrument at room temperature. The crystal data were collected on an Oxford Diffraction Xcalibur Atlas Gemini ultra. High-resolution mass spectrometric experiments were performed with a Bruker 7-Tesla FT-ICR mass spectrometer equipped with an electrospray source (Billerica, MA, USA). The fluorescence experiments were conducted on a RF-5301 spectrofluorophotometer (Shimadzu Corporation, Japan). The melting point was collected on a SHPSIC WRS-2 automatic melting point apparatus 


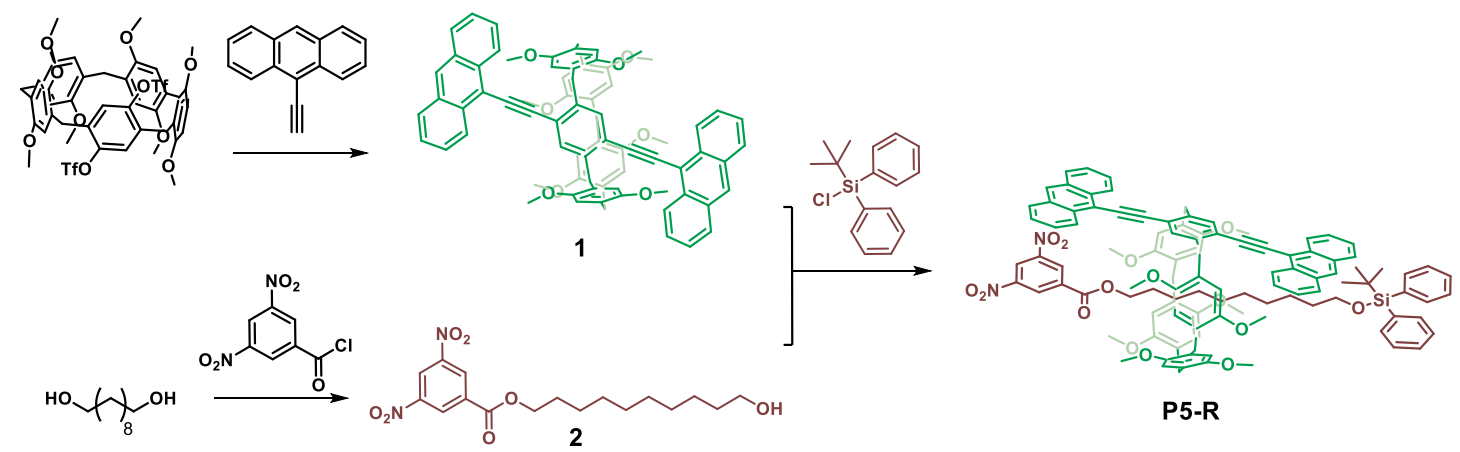

Scheme S1. Synthesis of 1, 2 and P5-R.

Compound 1 was prepared according to published procedures. ${ }^{[\mathrm{S} 1]}$ To a solution of 9-ethynylanthracene $(0.55 \mathrm{~g} \mathrm{~g}, 2.7 \mathrm{mmol})$ and ditriflic pillar[5]arene (1.00 g, 0.90 mmol) was added $\mathrm{Pd}\left(\mathrm{Ph}_{3} \mathrm{P}\right)_{2} \mathrm{Cl}_{2}(252 \mathrm{mg}, 0.36 \mathrm{mmol})$ in a mixture of triethyl amine (4.00 mL) and DMF (16.0 mL). The solution was heated to $90{ }^{\circ} \mathrm{C}$ via oil bath for $12 \mathrm{~h}$ under protection of argon. After quenched with water, the precipitate was collected and purified on column chromatography by silica gel using hexane : dichloromethane $=1: 1$ as eluent to obtain compound 1 as a yellow solid $(0.76 \mathrm{~g}$, yield $76 \%)$. The ${ }^{1} \mathrm{H}$ NMR spectrum is consistent with previous reports. ${ }^{1} \mathrm{H}$ NMR $\left(500 \mathrm{MHz}, \mathrm{CDCl}_{3}, 298\right.$ K) $\delta(\mathrm{ppm}): 8.82(\mathrm{~d}, J=8.4 \mathrm{~Hz}, 4 \mathrm{H}), 8.46(\mathrm{~s}, 2 \mathrm{H}), 8.07(\mathrm{~d}, J=8.2 \mathrm{~Hz}, 4 \mathrm{H}), 7.97(\mathrm{~s}$, 2H), $7.60(\mathrm{dt}, J=14.3,6.7 \mathrm{~Hz}, 8 \mathrm{H}), 7.16(\mathrm{~s}, 2 \mathrm{H}), 6.89(\mathrm{~s}, 2 \mathrm{H}), 6.76(\mathrm{~s}, 2 \mathrm{H}), 6.68$ (s, 2H), $4.41(\mathrm{dd}, J=37.5,13.2 \mathrm{~Hz}, 4 \mathrm{H}), 3.88(\mathrm{~s}, 6 \mathrm{H}), 3.80-3.70(\mathrm{~m}, 6 \mathrm{H}), 3.65(\mathrm{~s}, 6 \mathrm{H})$, $3.53(\mathrm{~s}, 6 \mathrm{H}), 2.96(\mathrm{~s}, 6 \mathrm{H})$. 

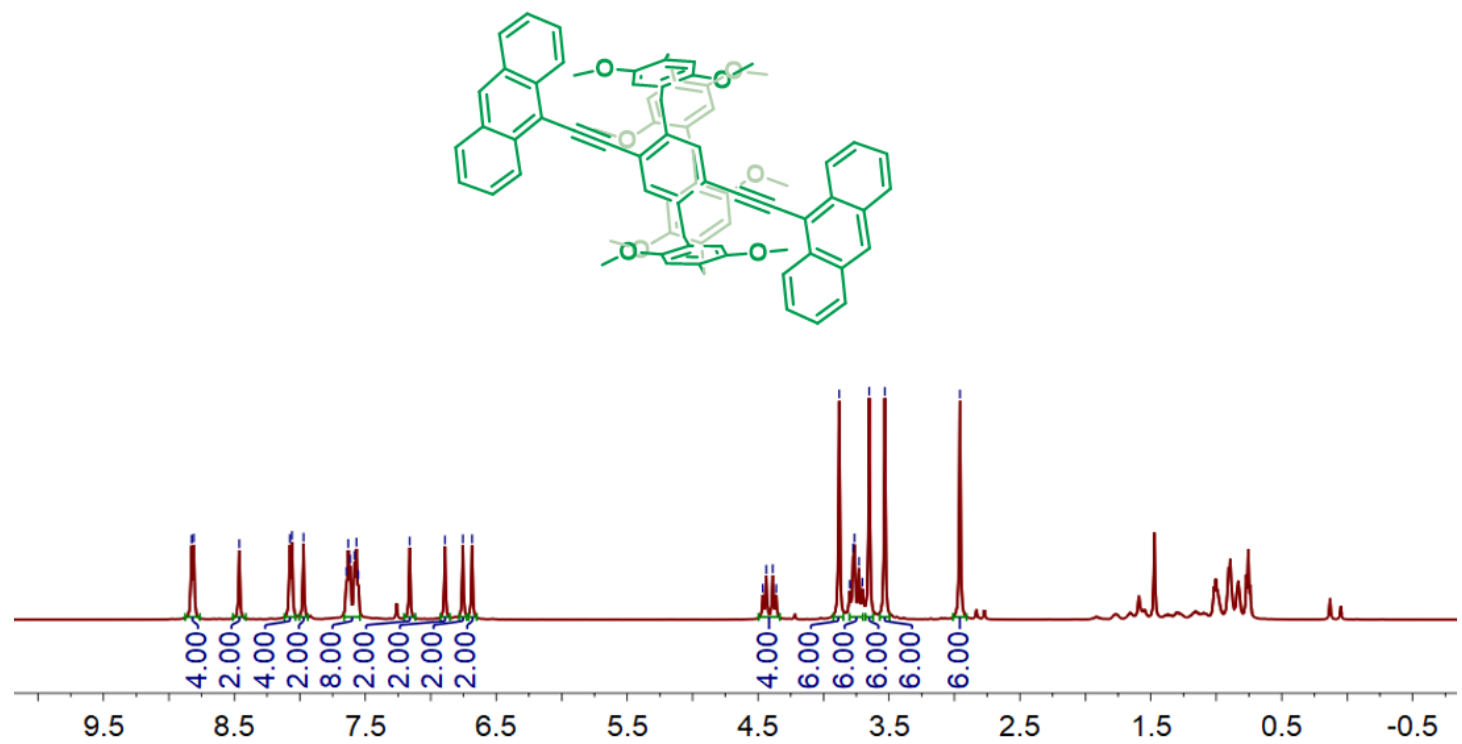

Figure S1. ${ }^{1} \mathrm{H}$ NMR spectrum $\left(500 \mathrm{MHz}, \mathrm{CDCl}_{3}, 298 \mathrm{~K}\right)$ of $\mathbf{1}$.

Compound 2 was prepared with an optimized method according to previous reports. ${ }^{[\mathrm{S} 2]} 1,10$-Decanediol $(1.74 \mathrm{~g}, 10.0 \mathrm{mmol})$ and $5.00 \mathrm{~mL}$ of triethyl amine were dissolved in $50.0 \mathrm{~mL}$ of dichloromethane. 3,5-Dinitrobenzoyl Chloride (1.15 g, 5.00 $\mathrm{mmol}$ ) in $10.0 \mathrm{~mL}$ of dicholoromethane was added dropwise for $1 \mathrm{~h}$. After stirring for additional $3 \mathrm{~h}$, the reaction was quenched with water. The organic layer was concentrated and purified on column chromatography by silica gel using hexane : dichloromethane $=1: 1$ as eluent to obtain compound $\mathbf{2}$ as a light yellow solid $(3.01 \mathrm{~g}$, yield $81.8 \%$ ). ${ }^{1} \mathrm{H}$ NMR (500 MHz, $\left.\mathrm{CDCl}_{3}, 298 \mathrm{~K}\right) \delta(\mathrm{ppm}): 9.16(\mathrm{~s}, 1 \mathrm{H}), 9.09(\mathrm{~s}, 2 \mathrm{H})$, $4.38(\mathrm{t}, J=6.8 \mathrm{~Hz}, 2 \mathrm{H}), 3.57(\mathrm{t}, J=6.6 \mathrm{~Hz}, 2 \mathrm{H}), 1.79-1.74(\mathrm{~m}, 2 \mathrm{H}), 1.52-1.47(\mathrm{~m}$, $2 \mathrm{H}), 1.40(\mathrm{~s}, 4 \mathrm{H}), 1.26(\mathrm{~m}, 8 \mathrm{H})$. 

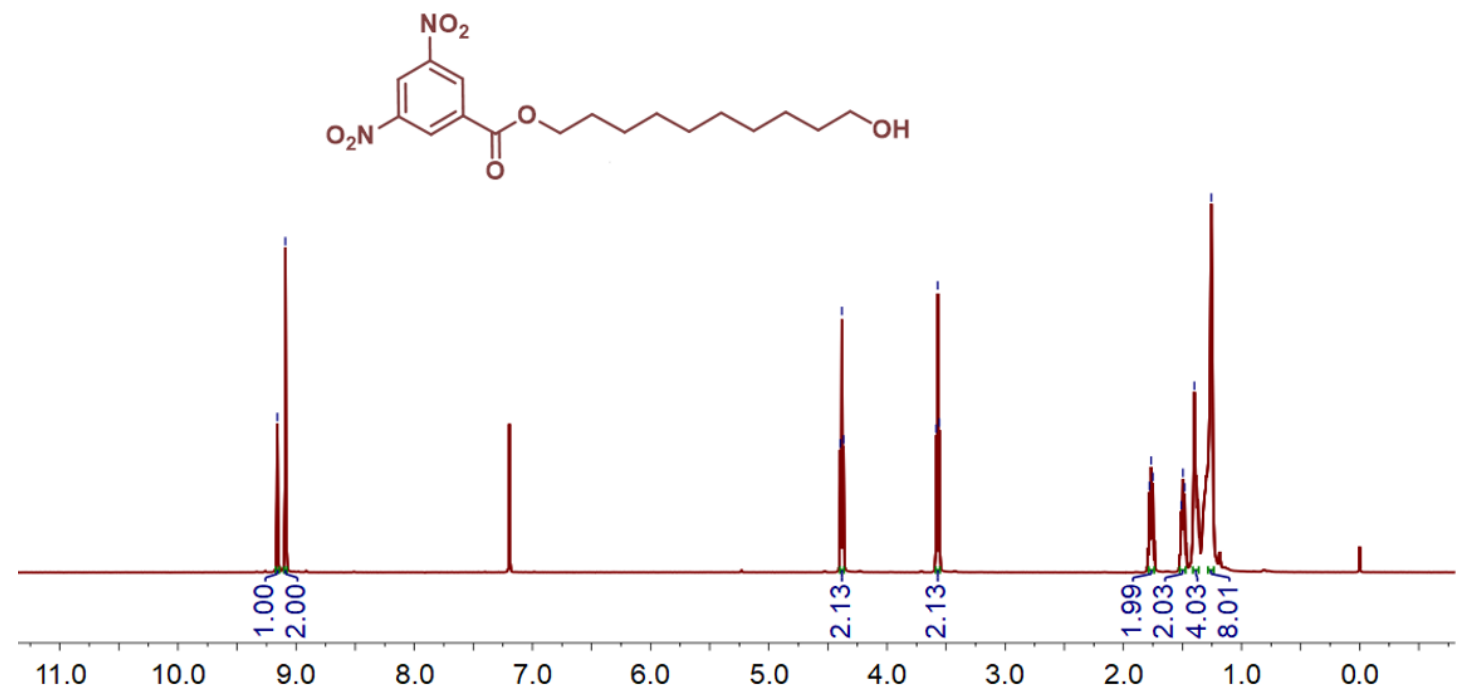

Figure S2. ${ }^{1} \mathrm{H}$ NMR spectrum $\left(500 \mathrm{MHz}, \mathrm{CDCl}_{3}, 298 \mathrm{~K}\right)$ of 2.

The rotaxane P5-R: Compound 1 (109 mg, $0.10 \mathrm{mmol})$ and 2 (368 mg, $1.00 \mathrm{mmol})$ were mixed in $5.00 \mathrm{~mL}$ of chloroform and stirred at room temperature for $1 \mathrm{~h}$ to form a psudorotaxane. After adding $50.0 \mathrm{mg}$ of imidazole as a base and catalytic amount of 4-dimethylaminopyridine, TBDPSCl $(54.8 \mathrm{mg}, 0.20 \mathrm{mmol})$ was added and the mixture was stirred for addtional $3 \mathrm{~h}$. The solution was concentrated and the crude product was purified on column chromatography by silica gel using hexane : dichloromethane $=1: 2$ as eluent to obtain P5-R as an orange solid $(121 \mathrm{mg}$, yield $71.2 \%$ ). The structure of P5-R was confirmed by X-ray single crystal analysis. m.p. 171.1-176.3 ${ }^{\circ} \mathrm{C} .{ }^{1} \mathrm{H}$ NMR $\left(500 \mathrm{MHz}, \mathrm{CDCl}_{3}, 298 \mathrm{~K}\right) \delta(\mathrm{ppm}): 9.21(\mathrm{~s}, 1 \mathrm{H}), 9.16(\mathrm{t}, \mathrm{J}=$ $17.5 \mathrm{~Hz}, 2 \mathrm{H}), 8.85$ (d, $J=8.6 \mathrm{~Hz}, 2 \mathrm{H}), 8.69$ (s, 1H), 8.60 (d, $J=8.6 \mathrm{~Hz}, 2 \mathrm{H}), 8.28$ (s, $1 \mathrm{H}), 8.17-8.15(\mathrm{~m}, 3 \mathrm{H}), 8.12(\mathrm{~s}, 1 \mathrm{H}), 8.06(\mathrm{~s}, 1 \mathrm{H}), 7.92(\mathrm{~d}, J=8.5 \mathrm{~Hz}, 2 \mathrm{H}), 7.74-7.71$ (m, 4H), $7.63-7.60(\mathrm{~m}, 4 \mathrm{H}), 7.42(\mathrm{~m}, 10 \mathrm{H}), 7.08(\mathrm{~s}, 1 \mathrm{H}), 6.93(\mathrm{~d}, J=6.6 \mathrm{~Hz}, 2 \mathrm{H})$, 6.77-6.74 (m, 3H), 4.39 (m, 6H), 4.10 (s, 3H), 4.01 (s, 3H), 3.83-3.65 (m, 6H), 3.64 (s, 3H), 3.63 (s, 3H), 3.57 (s, 3H), 3.51 (s, 3H), 3.49 (s, 3H), $3.40-3.28$ (m, 2H), 2.98 (s, 3H), 1.82 (d, J=7.7 Hz, 2H), 1.58 (s, 4H), 1.03 (s, 9H), $0.73-0.61$ (m, 2H), -0.19 $(\mathrm{m}, 2 \mathrm{H}),-0.57(\mathrm{~m}, 2 \mathrm{H}),-1.86(\mathrm{~m}, 2 \mathrm{H}),-2.14(\mathrm{~m}, 2 \mathrm{H}) .{ }^{13} \mathrm{C}$ NMR spectrum $(100 \mathrm{MHz}$, $\left.\mathrm{CDCl}_{3}, 298 \mathrm{~K}\right) \delta(\mathrm{ppm}): 164.3(\mathrm{~s}), 153.2,152.8,151.3,150.0,143.7,143.2,138.5$, $137.4,135.1,134.6,133.9,133.5,132.2$, 132.0, 131.6, 131.1, 130.5, 130.3, 129.9, $129.6,129.4,129.2$, 128.8, 128.6, 128.4, 124.9, 123.5, 120.0, 117.0, 116.4, 116.0, $115.8,115.5,115.2,104.8,94.2,93.3,70.6,69.7,66.6,59.1,58.5,58.0,57.9,57.8$, 
57.7, 57.5, 57.4, 37.0, 36.7, 35.4, 34.1, 33.5, 33.1, 32.9, 32.3, 32.0, 31.8, 31.5, 31.2, $29.5,29.2,28.8,28.5,25.0,21.8,3.7,2.6$. This product was hardly ionized in ESI mass spectrometer, and thus we used MALDI-TOF mass to exam its molecular weight. MS (MALDI-TOF) m/z: [M + H] $]^{+}$Calcd for $\mathrm{C}_{108} \mathrm{H}_{105} \mathrm{~N}_{2} \mathrm{O}_{15} \mathrm{Si}$ 1697.7284; found 1698.0714

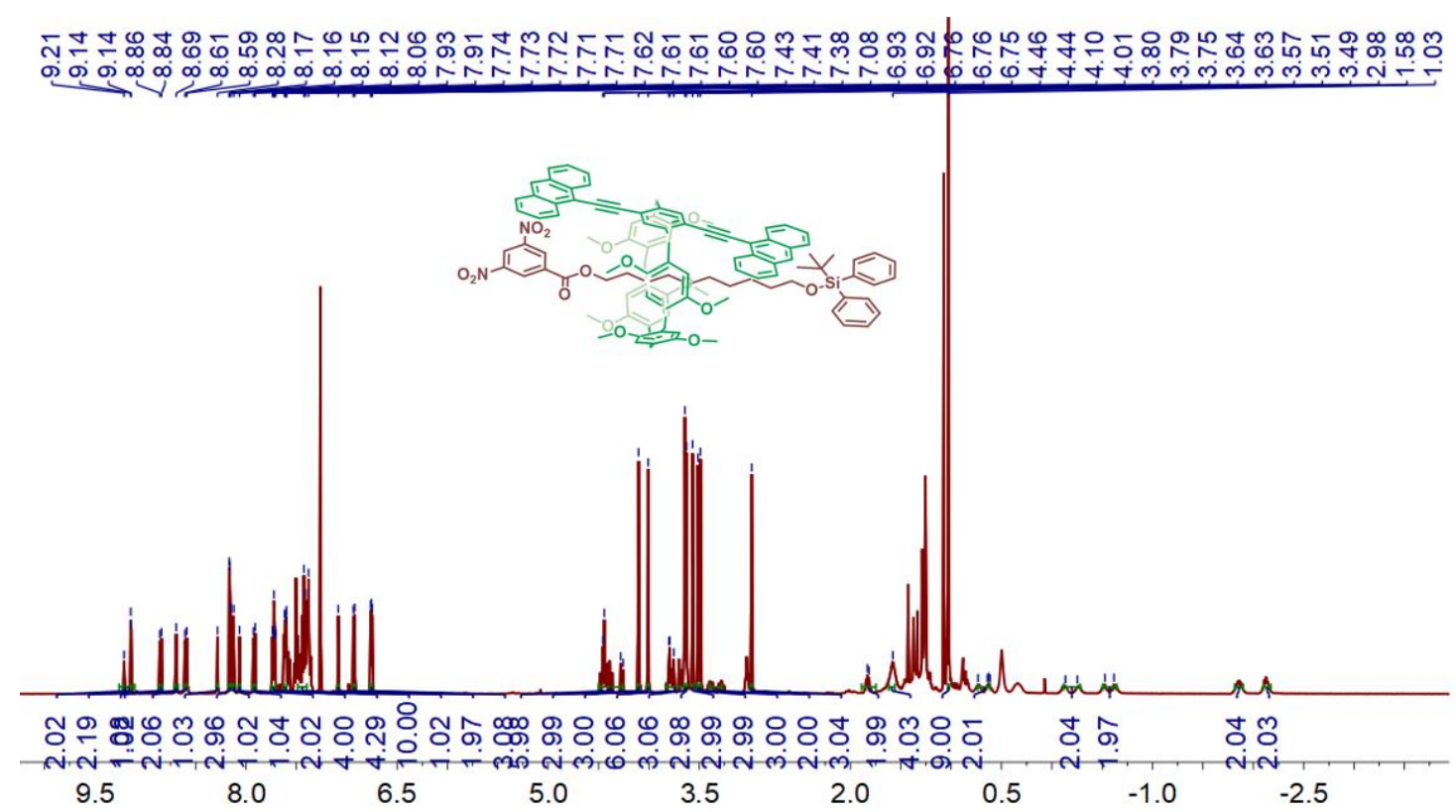

Figure S3. ${ }^{1} \mathrm{H}$ NMR spectrum (500 MHz, $\mathrm{CDCl}_{3}, 298 \mathrm{~K}$ ) of P5-R.

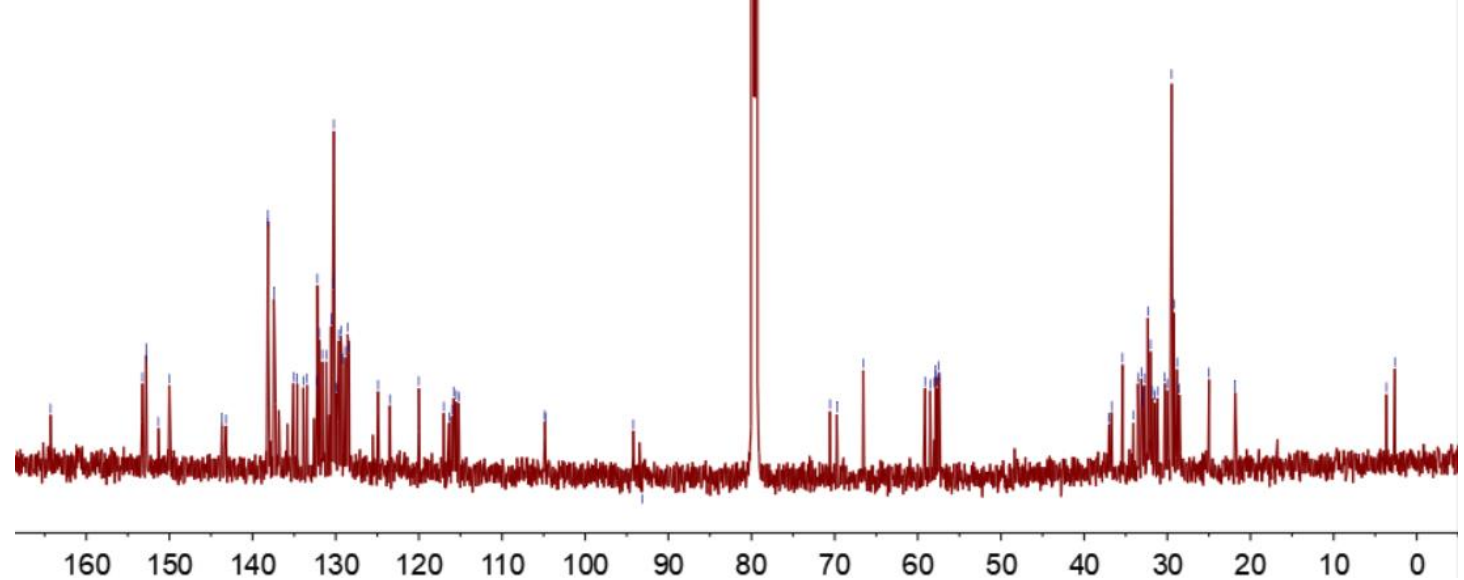

Figure S4. ${ }^{13} \mathrm{C}$ NMR spectrum $\left(125 \mathrm{MHz}, \mathrm{CDCl}_{3}, 298 \mathrm{~K}\right)$ of P5-R. 
MALDI-TOF Mass Spectrum

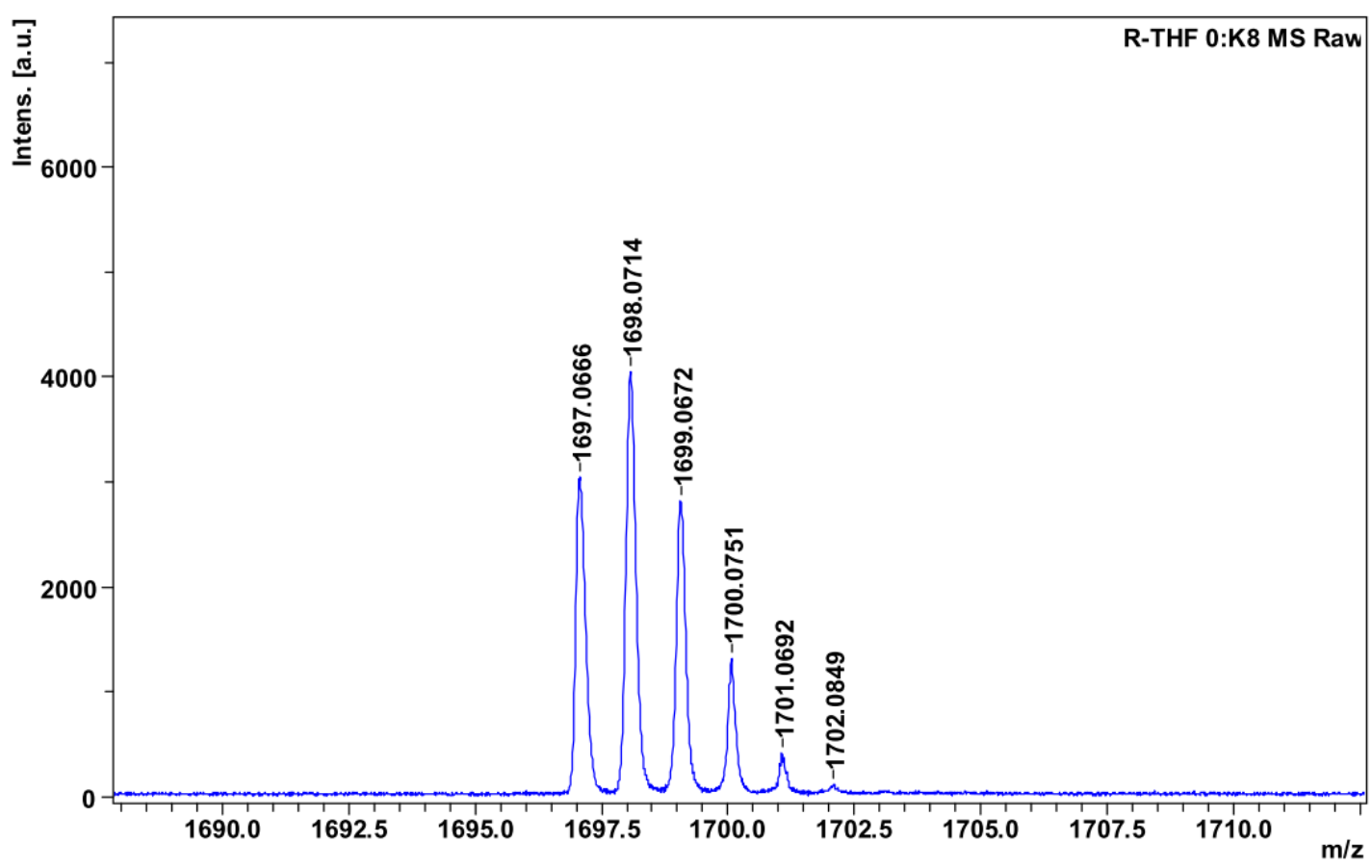

Figure S5. MALDI-TOF mass spectrum of P5-R with isotope distributions. 


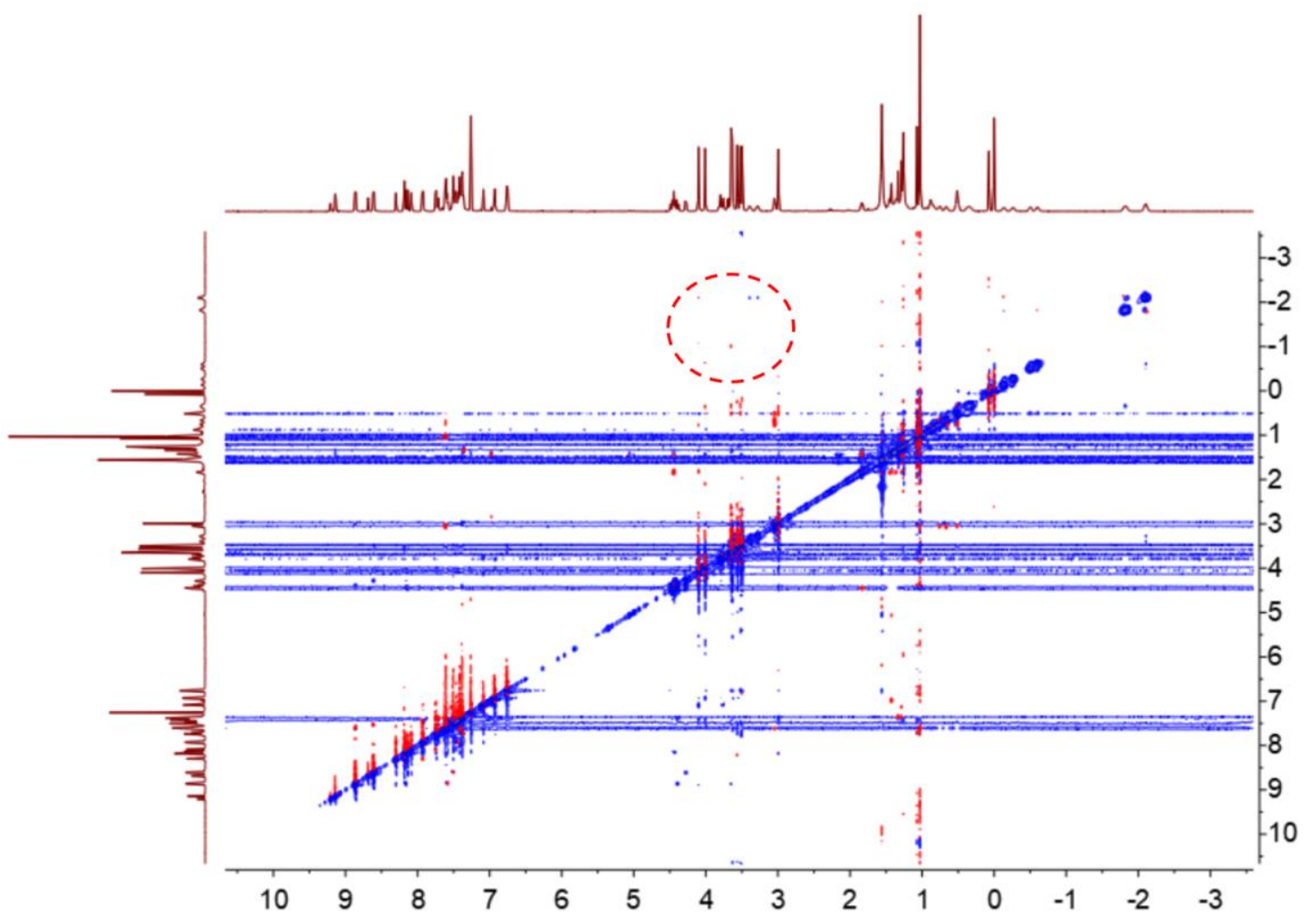

Figure S6. NOESY spectrum $\left(500 \mathrm{MHz}, \mathrm{CDCl}_{3}, 298 \mathrm{~K}\right)$ of P5-R. 
4. $U V$-vis spectrua of P5-R before and after adding fluoride anion

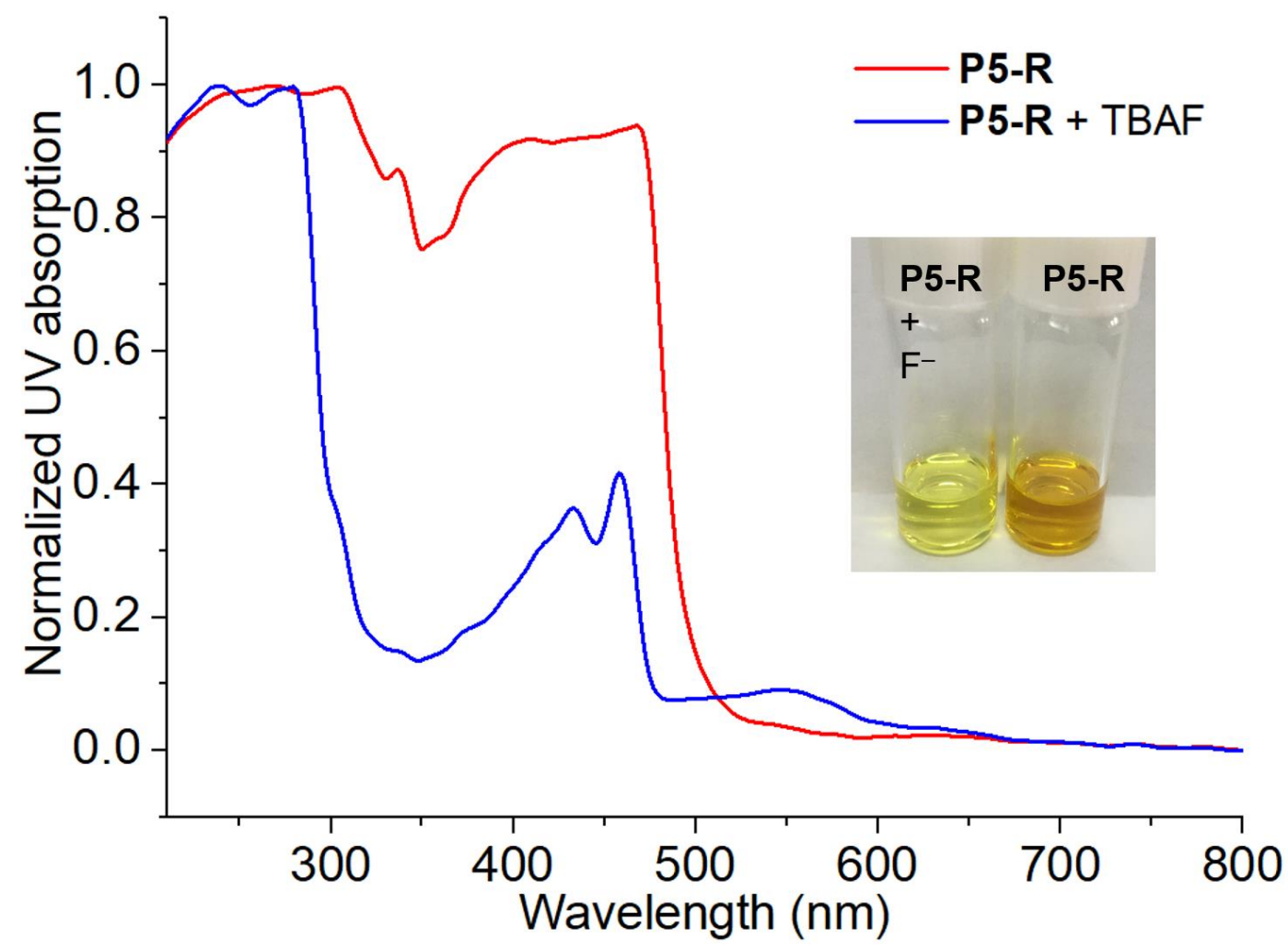

Figure S7. Normalized UV absorption of P5-R $\left(1.00 \times 10^{-5} \mathrm{M}\right)$ before and after adding TBAF (50.0 eq.). 


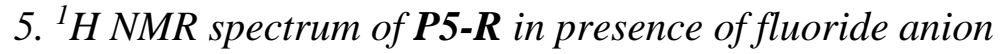

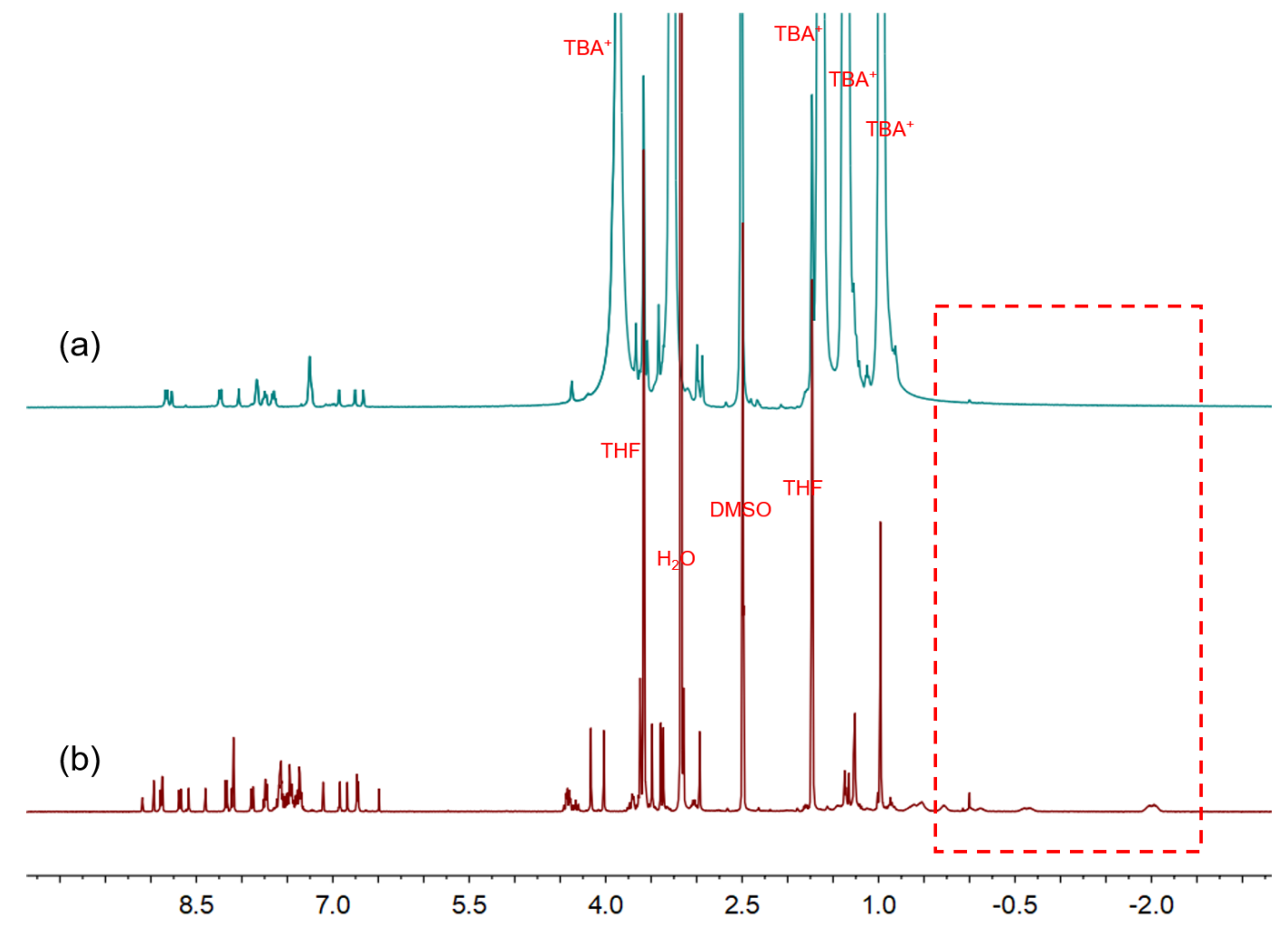

Figure S8. ${ }^{1} \mathrm{H}$ NMR spectra $\left(500 \mathrm{MHz}, \mathrm{DMSO}-d_{6}:\right.$ THF- $\left.d_{8}=1: 1,298 \mathrm{~K}\right)$ of P5-R $(5.00 \mathrm{mM})$ in (a) presence and (b) absence of fluoride anion. The peaks of solvents and TBA cation are marked. The dash line box indicates the disappearance of threading protons and diassembly of the rotaxane structure after adding fluoride anion. 
6. MALDI-TOF spectrum of P5-R in presence of fluoride anion

MALDI-TOF Mass Spectrum

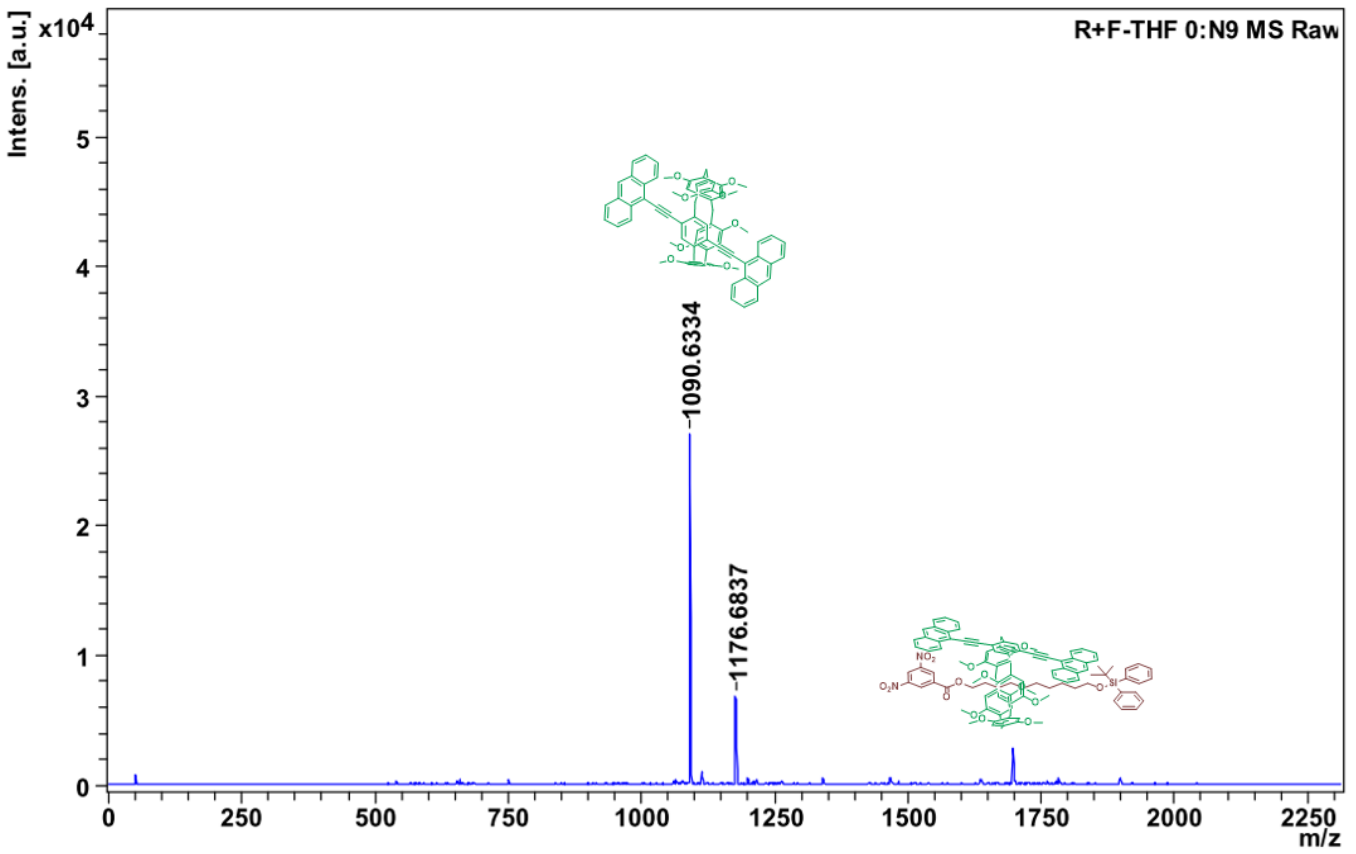

Figure S9. MALDI-TOF mass spectrum of P5-R in presence of fluoride anion. The peak with $m / z, 1090.6334$ indicates the disassembled 'wheel'. 
7. Time-dependent fluorescence spectra
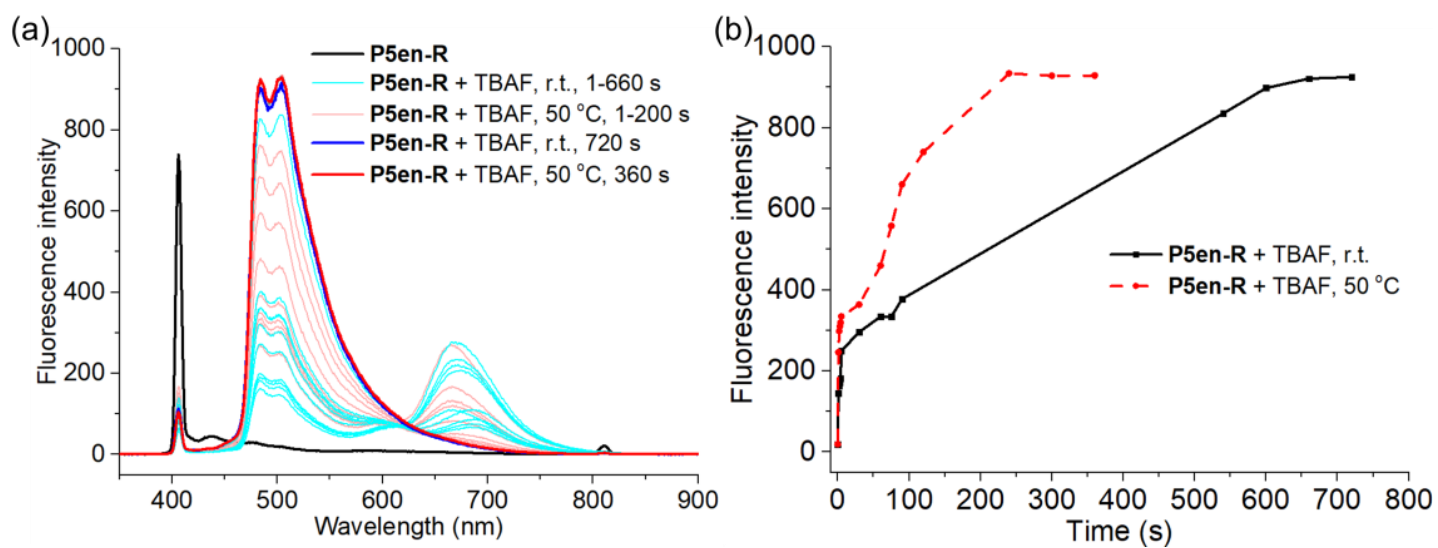

Figure S10. (a) Time-dependent fluorescence spectra of P5-R $\left(1.00 \times 10^{-4} \mathrm{M}\right.$ in $\mathrm{DMSO} / \mathrm{THF}=1: 1)$ in presence of 50.0 equiv. of fluoride anion at different temperature. (b) Fluorescence changes at $504 \mathrm{~nm}$. 


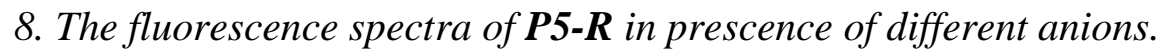

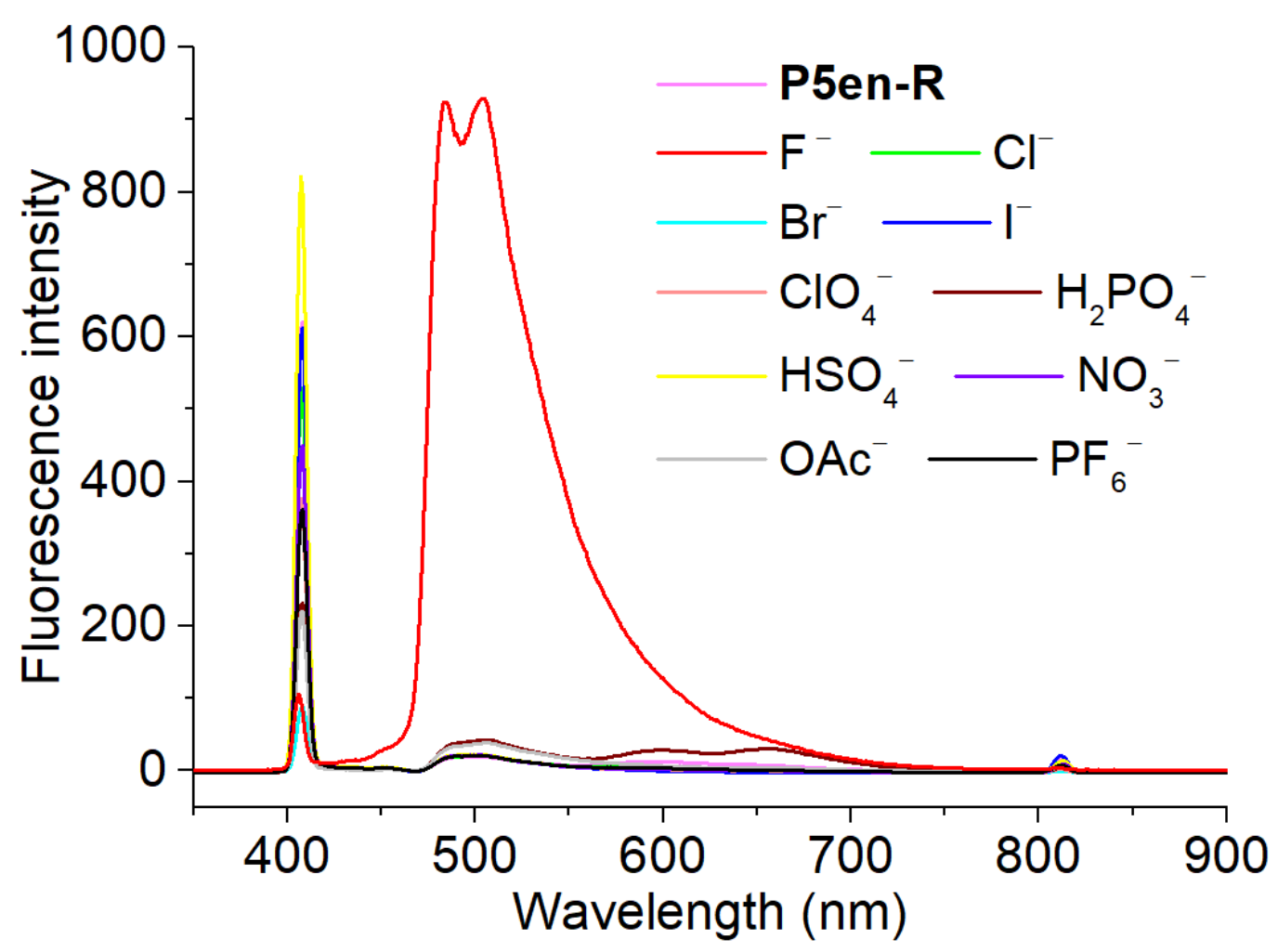

Figure S11. Fluorescence spectra of P5-R $\left(1.00 \times 10^{-4} \mathrm{M}\right.$ in DMSO/THF $\left.=1: 1\right)$ in presence of different anions. The fluorescence was measured after the reaction completion. 


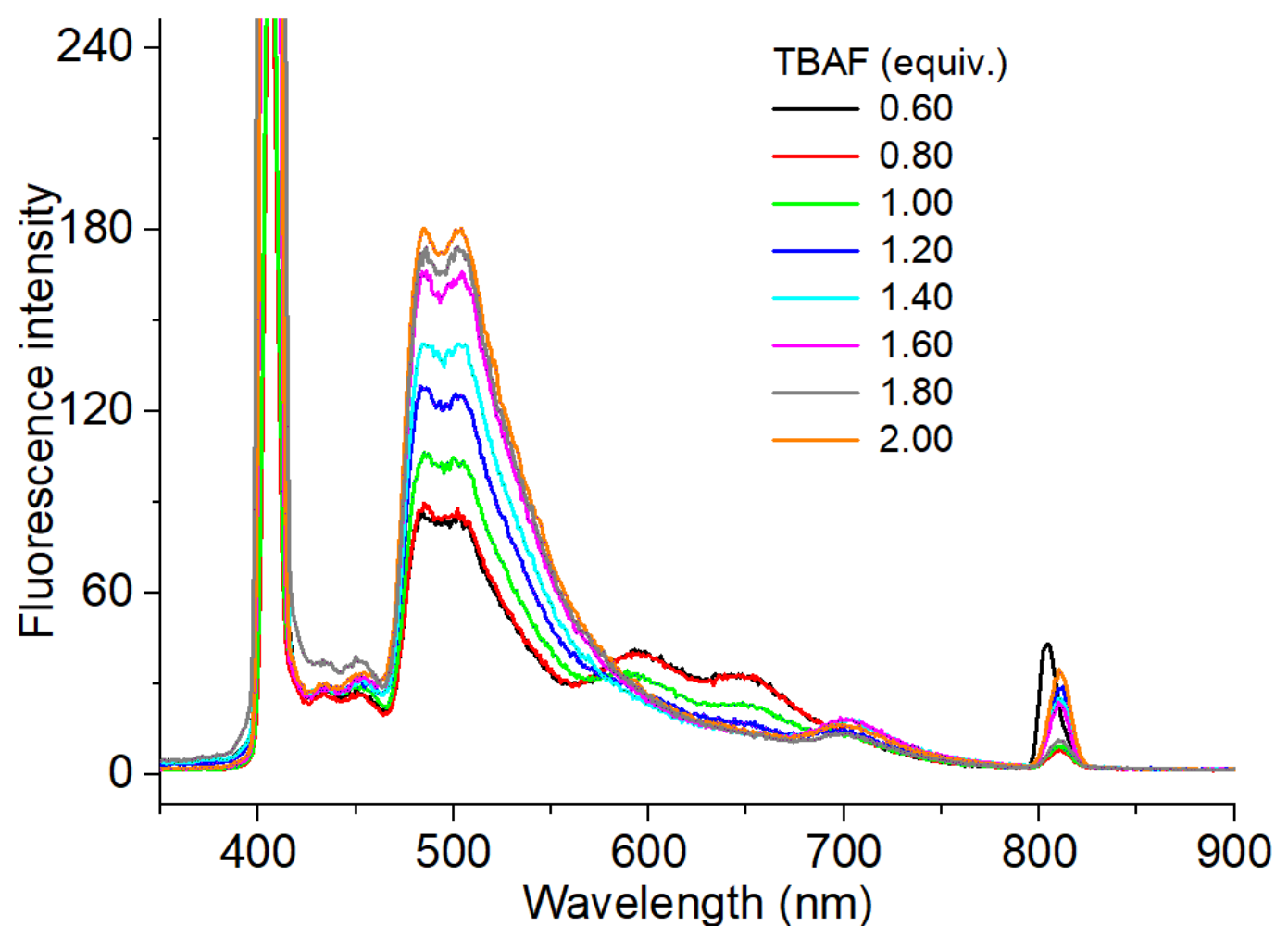

Figure S12. Fluorescence titration between P5-R $\left(1.00 \times 10^{-5} \mathrm{M}\right.$ in DMSO/THF $=$ $1: 1)$ and fluoride anion from 0.60 to 2.00 equivalents. The fluorescence was measured after the reaction completion.

The standard deviation $(S d)$ of blank measurements was calculated according to measuring the fluorescence intensity of the rotaxane for 10 times. The collected date: 81.828, 81.924, 81.687, 81.68, 83.202, 80.324, 81.181, 83.477, 79.691, 81.194. Calculated Sd: 1.148418313. 


\section{X-ray crystal data for P5-R}

Crystallographic data: block, orange, $0.15 \times 0.10 \times 0.08 \mathrm{~mm}^{3}, \mathrm{C}_{108} \mathrm{H}_{104} \mathrm{O}_{15} \mathrm{~N}_{2} \mathrm{Si}, F W$ 1698.02, monoclinic, space group $P 2{ }_{1} / c, a=22.6341(7), b=17.9841(5), c=$ 23.6662(6) $\AA, \alpha=90.00^{\circ}, \beta=98.872(2)^{\circ}, \gamma=90.00^{\circ}, V=9518.2(5) \AA^{3}, Z=4, D_{c}=$ $1.185 \mathrm{~g} \mathrm{~cm}^{-3}, T=169.96 \mathrm{~K}, \mu=0.477 \mathrm{~mm}^{-1}, 18134$ measured reflections, 14172 independent reflections, 1146 parameters, 0 restraints, $F(000)=3600, R($ int $)=0.0000$, $R_{1}=0.0752, w R_{1}=0.1709$ (all data), $R_{2}=0.0613, w R_{2}=0.1819[I>2 \sigma(I)]$, max. residual density $0.846 \mathrm{e} \bullet \AA^{-3}$, and goodness-of-fit $\left(F^{2}\right)=1.053$. CCDC 2009181 . 


\section{The association constant between 1 and 2}

(a)

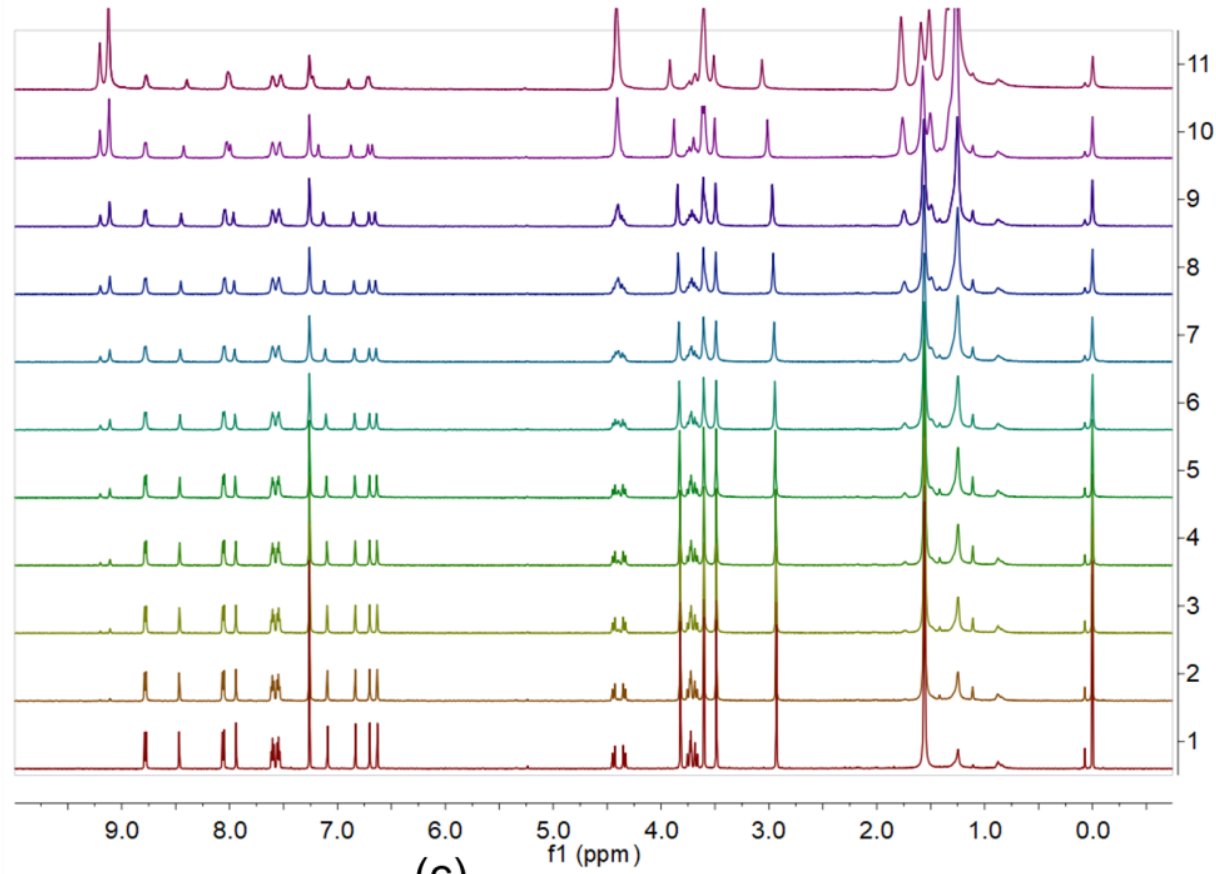

(b)

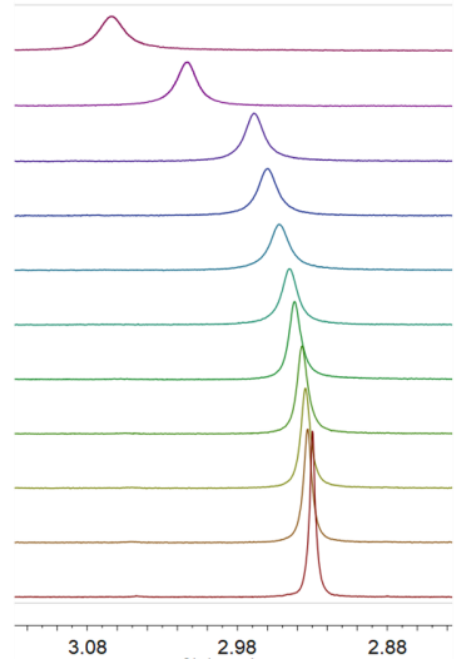

(c)

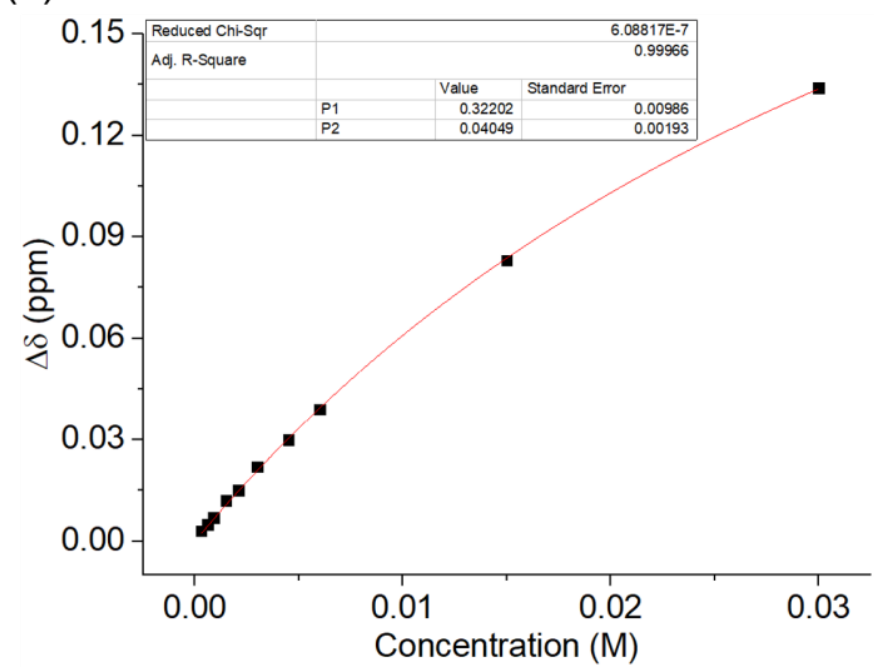

Figure S13. (a) NMR titration between 1 and 2. (b) Magnified NMR spectra of the titration procedure. (c) Non-linear curve fitting of the titration procedure. The association constant was determined to be $24.69 \mathrm{M}^{-1}$.

\section{References:}

S1. Li, Q.; Zhu, H.; Huang, F. J. Am. Chem. Soc. 2019, 141, 13290-13294.

S2. Dong, S.; Han, C.; Zheng, B.; Zhang, M.; Huang, F. Tetrahed. Lett. 2012, 53 3668-3671. 